News and notes

\section{Ethics of research in relation to human subjects/patients}

Earlier this year the Royal College of Physicians published two reports: Guidelines on the Practice of Ethics Committees in Medical Research involving Human Subjects (second edition) and Research Involving Patients.

The 'Guidelines' report states that the objectives of research ethics committees are 'to maintain, ethical standards of practice in research, to protect subjects of research from harm, to preserve the subjects' rights and to provide reassurance to the public that this is being done'.

While conceding that the definition of research continues to present difficulties the report goes on to provide a useful distinction between medical practice and medical research - the distinction deriving from the intent.

'In medical practice the sole intention is to benefit the individual patient consulting the clinician, not to gain knowledge of general benefit, though such knowledge may incidentally emerge from the clinical experience gained. In medical research the primary intention is to advance knowledge so that patients in general may benefit; the individual patient may or may not benefit directly'.

Section 4.1 of the report states that 'all medical research involving human subjects should undergo ethical review before it commences, in accordance with the principle that investigators should not be the sole judge of whether their research raises significant ethical issues'.

Under the heading Terms of reference and scope, the report says an ethics research committee should:

a Advise its appointing authority on all matters pertaining to the ethics of research involving human subjects;

b Review proposals for research to be carried out in the institution or area of that authority;

c Review proposals for research to be carried out by staff of the authority in other places where there is no ethics committee. Note: Where the other place has an ethics committee, the committee of the home institution need not necessarily be involved; d Not undertake functions that might conflict with the above, for example it should not act as a researchfunding or grant-giving committee;

e Make an annual, or more frequent, report to the appointing authority, which should be made available to the public (see 7.12).

Section 11 deals with consent to participation in research.

11.2 'It has often been suggested that where a randomised controlled trial is undertaken to compare conventional treatment with a novel treatment, then consent need formally be sought only from patients to whom the new treatment is allocated (see 9.3). This technique (post-randomisation consent) involves withholding information on treatment options from patients and is generally unacceptable for that reason. However, there can be exceptions, for example, in population-based trials or rarely in smaller studies.'

Dealing with the meaning of consent the report goes on to say that "the terms "valid", "informed" and "voluntary" imply that subjects have enough information, in a form that is comprehensible, to enable them to make an autonomous, deliberated (proper) judgement whether or not to participate. The word "consent" encompasses these requirements, for if they are not met there is no consent. The use of qualifying adjectives is unnecessary and may even be confusing.'

The report also covers: membership of committees; method of working; applications to ethics committees; therapeutic trials; responsibilities in law; healthy (nonpatient) volunteers and patient volunteers; special classes of research; research involving fetuses, fetal material, in vitro fertilisation and embryos; development and official regulation of medicines (Medicines Act 1968); injuries due to clinical investigations, and payments.

The second report, Research involving Patients, includes chapters on: justification for research involving patients; the role of research ethics committees: assessment of the ethics of research; assessing the quality of research; initial selection of patients; recruitment of patients (with large subsections on consent, inducements and randomised controlled therapeutic trials); conduct of research; 
ownership of results of research; monitoring the conduct of research, and legal implications and arrangements for compensation.

The final chapter contains 60 recommendations which deal with: the role of research ethics committees; assessing the aims, quality, risks and benefits of research; selection of patients and use of medical records; recruitment of patients (five of the recommendations under this heading are to do with consent); research involving children; research involving mentally handicapped patients; research involving the mentally ill; research involving prisoners; research involving severely ill patients; research involving pregnant patients; research involving elderly patients; initiation of research without consent; inducements to patients; inducements to researchers; randomised controlled therapeutic trials; conduct of research; monitoring the conduct of research, and arrangements for compensation.

Both reports are available from the Royal College of Physicians at a cost of $£ 8.00$ each. The two publications may be purchased together, at a price of $£ 14.00$.

\section{Tennent Caledonian and Royal Bank of Scotland Research Fellowships 1991-92}

Applications are invited for these Research Fellowships for the academic session 1991-92.

The fellowships are intended primarily, though not exclusively, for philosophers and political theorists on study leave from their own universities or colleges. Appointment is normally for one term and the fellowship carries a travel allowance, accommodation in St Andrews and a room in the Department of Moral Philosophy, and access to word-processing facilities. Further details are available from the Director, Dr John Haldane, Centre for Philosophy and Public Affairs, University of St Andrews.

Applications, including a cv, a short statement of research intentions or plans, and an indication of the term during which the fellowship would be held should be submitted no later than 16 November 1990 (though early applications are welcome) to: The Director of Personnel Services, College Gate, University of St Andrews, North Street, St Andrews, Fife KY16 9AJ, Scotland.

\section{International information on embryo research published}

Virginia Bottomley, Minister for Health, has announced the publication of a report, Human in Vitro Fertilisation, Embryo Research, Fetal Tissue for Research and Treatment, and Abortion: International Information, looking at embryo research in other countries.

Mrs Bottomley said: 'I have today arranged for a copy of this research report to be placed in the library. It was commissioned by the Department of Health in recognition of the need for up-to-date, accurate information on these subjects. In particular the introduction of the Human Fertilisation and Embryology Bill has focussed attention on the approach taken in other countries to the questions raised by the Bill.

The study was undertaken by Dr Jennifer Gunning, until recently Secretary of the Interim Licensing Authority.

Mrs Bottomley said: 'The report is a survey of the legislation and current practice in a number of countries. It does not attempt to analyse the merits of any particular approach and no conclusions are drawn.'

\section{Staff openings at the Hastings Center}

The Hastings Center expects to have openings at the following levels commencing on or before September 1, 1990:

\section{Editor}

The editor of the Hastings Center Report retains overall supervision and responsibility for editorial content and production of a bimonthly magazine, and its additional special supplements. This includes responsibility for commissioning articles, managing review process for all invited and unsolicited manuscripts, editing and copy editing, contact with authors, proofreading, working with production manager on layout, writing features, correspondence, working with membership department on promotion, phone inquiries, and all the other details attendant to publishing of the magazine. The center is particularly interested in candidates with a strong background in bioethics and cognate fields. We especially encourage people with backgrounds in journalism and publishing from a wide variety of disciplines.

\section{Associate}

An associate occupies a professional level position on the staff of the center and, under the supervision of the director, is expected to provide significant intellectual and managerial leadership for all facets of the center's work. The associate's duties require a combination of solid administrative skills, scholarly productivity, intellectual creativity, an ability to write rapidly and effectively, and a capacity to plan activities carefully and to meet strict deadlines.

Associates direct and supervise externally funded research projects, and they also participate in center educational programs. Associates are expected to sustain a vigorous, productive career of writing and scholarship in their own field. In addition they are expected, over time, to make significant contributions to the field of bioethics through publications growing out of center projects and through their independent publications and research.

The center is particularly interested in candidates with a strong background in the field of bioethics, and especially encourages applications from those from the 